\title{
Arte de la tierra: experiencias de creación en la tierra
}

\author{
Land Art: Experiences of Creation on the Land \\ Diana Paola Melo Sánchez ${ }^{1}$ Keryn Gualteros Solorza²
}

Para citar este artículo: Melo, D. P.; Gualteros, K. (2017).

Recibido: 23-mayo-2016 / Aprobado: 20-agosto-2017

Arte de la tierra: experiencias de creación en la tierra. In-

fancias Imágenes, 16(2), 272-281.

\section{Resumen}

Este artículo es producto de la investigación en la línea: arte de la tierra ${ }^{3}$, realizada por estudiantes de Licenciatura en Pedagogía Infantil (LPI) de la Universidad Distrital Francisco José de Caldas (UDFJC) con estudiantes de primera infancia en la Escuela Pedagógica Experimental (EPE). Los objetivos fueron: observar qué percepciones tienen niños y niñas acerca de su territorio, afianzar la conciencia ambiental, vivenciar y entender el proceso de siembra orgánica a partir de la creación con elementos naturales. Lo anterior, materializado en una huerta estética ${ }^{4}$ asumida como tejido social y aula viva, donde se tratan temas como: seguridad alimentaria, tradición e importancia de plantas medicinales y ancestrales. Este proceso se asume como una alternativa de trabajo pedagógico basada en la tendencia artística de arte procesual ${ }^{5}$, enmarcada en la investigación cualitativa, bajo el enfoque de investigación-acción educativa; esto permite la reflexión ambiental y la participación creativa de la comunidad de La Calera.

Palabras clave: creación cultural; sensibilización ambiental; planta medicinal; participación comunitaria; narración; educación alternativa.

\begin{abstract}
This article is a product of the research in the contour: Land Art, carried out by undergraduate students in Pedagogy for Children (LPI) of the Francisco José de Caldas District University (UDFJC), with early childhood students in the Experimental Pedagogical School (EPE). The main objectives were: to observe what perceptions children have about their territory, to strengthen environmental awareness, to experience and understand the process of organic planting from the creation with natural elements. The above, materialized in an aesthetic garden assumed as a social fabric and living classroom, covering topics such as food security, tradition and importance of medicinal and ancestral plants. This process is assumed as an alternative pedagogical work, based on the artistic tendency of process art, framed in qualitative research, under the educational research-action approach, allowing environmental reflection and creative participation of the community of La Calera.
\end{abstract}

Keywords: cultural creation; environmental sensitization; medicinal plant; community participation; narration; alternative education.

\footnotetext{
1 Licenciada en Pedagogía Infantil, Universidad Distrital Francisco José de Caldas. Correo electrónico: diannis-23@hotmail.com

2 Licenciada en Pedagogía Infantil, Universidad Distrital Francisco José de Caldas. Correo electrónico: kerin.solorza@epe.edu.co

3 Arte de la tierra es, entonces, una denominación castiza de lo que en occidente se suele denominar Land Art. Como grupo de investigadoras nos interesamos por el pensamiento descolonizador que le apuesta a usar denominaciones a partir de lo que se ha construido desde América Latina.

4 Cuando nos referimos al proceso de siembra estética lo hacemos desde la noción de procesos de sensibilidad desde la noción artística y no desde los resultados de las representaciones culturales como "bello".

5 Intentar una definición del concepto arte procesual puede resultar una tarea algo compleja. Sin embargo, desde el ámbito artístico, por ejemplo, Guash (2000) plantea que el concepto se halla vinculado íntimamente a la concreción de unas acciones expresivas en las cuales lo más importante es el desarrollo, el proceso, y no tanto la culminación de una obra, de un producto estético característico de las artes plásticas objetuales (dibujo, pintura, escultura tradicional).
} 


\section{Introducción}

Este artículo pretende divulgar resultados de un proceso investigativo centrado en la reflexión ambiental al recuperar experiencias del relato infantil y creaciones artísticas derivadas de prácticas ancestrales. Este tema fue de gran interés para este grupo de niños y niñas, quienes, a través de su voz, nos hicieron descentralizar como docentes, dejando la mirada adulto-centrista para ver el interés de los niños y niñas frente al hacer natural desde el arte. Lo anterior nos llevó a realizar una recopilación de sus relatos y proponer el proyecto Siembra: experiencias de creación en la tierra ${ }^{6}$. Este nos dio la posibilidad de vivenciar el arte como práctica cultural expresiva, donde el ejercicio de pensamiento se construye con otros, desde la curiosidad innata del infante en relación con su entorno, promoviendo espacios de interacción que favorecen la construcción de relato desde un hacer consciente y reflexivo en las prácticas cotidianas.

De esta forma, vemos cómo el arte es una práctica cultural muchas veces no consciente que hace parte de nuestra identidad, siendo este el ejercicio en el cual lo impensable se hace pensable, en el que las mejores ideas salen a flote; recopilando así un saber propio y ancestral que conforma lo que somos. De esta forma, es necesario pensar este como un instrumento de conocimiento, en el que es relevante tomar esa curiosidad innata del ser inicial y su relación con el entorno para que se comiencen a generar experiencias de creación personales y colectivas; logrando así llegar de lo general a lo particular por medio de un enfoque artístico natural. A través del arte y la creación, por medio de elementos naturales, se evidencia cómo estos procesos son fundamentales en el diario aprendizaje de los niños y niñas. De este modo, se asume la exploración de una de las tendencias del arte procesual, el denominado arte de la tierra, el cual generó curiosidad e interés en los estudiantes.

\footnotetext{
6 Esta recopilación de los relatos infantiles se dio a partir del registro de las preguntas, percepciones e intervenciones en los diversos espacios explorados durante este proceso. Es a partir de lo anterior que se crea el documento escolar interno: Qué cuentan, qué dicen y qué preguntan los niños y niñas de Escuela Inicial de la Escuela Pedagógica experimental 2016.
}

Así, los propósitos de esta investigación fueron: evidenciar mediante el relato y las vivencias de conocimiento qué percepciones tenían los niños y niñas de su entorno natural y su relación con este; qué experiencias habían tenido con el relato ancestral y con el arte en la escuela; esto con el fin de generar nuevos espacios que enriquecieran su hacer experiencial y su acercamiento a un conocimiento ancestral. Se dio así potencia a la exploración y creación desde los componentes artístico-ambiental a partir de la siembra, el reconocimiento de los espacios alternativos de trabajo para finalmente realizar la construcción colectiva de la huerta como fuente de expresión y reflexión sobre el proceso. De ahí que el enfoque cualitativo se haya situado en los procesos de interacción entre los sujetos participantes, permitiendo así la socialización de saberes, la auto-reflexión, el diálogo como centro de descubrimiento y la transformación de la observación participativa directa dentro de un mismo colectivo.

\section{Localidad de estudio}

Uno de los escenarios de la construcción vivencial fue la EPE, ubicada en el kilómetro 4,5, vía La Calera, el cual es un espacio abierto periurbano donde el bosque hace de este una alternativa predilecta para el aprendizaje, pues no existen rejas ni puertas que indiquen en dónde empieza y en dónde termina. Un espacio educativo que le apuesta al aprendizaje colectivo desde tres pilares fundamentales: confianza, conocimiento y convivencia. En el que no existen uniformes, ni curriculum que direccione el hacer escolar a partir de las interacciones cotidianas de conocimiento; dando sentido al construir para la participación activa y democrática en la sociedad.

Lo anterior presupone construir con los niños y niñas un conocimiento de base sólido de nuestra historia y de las problemáticas nacionales, una capacidad en el dominio del lenguaje, la polémica y la discusión y una actitud crítica, racional, participativa y comprometida como individuo activo que más que buscar la adaptación se proyecte como un transformador crítico de la sociedad, involucrando las artes como extensión del ser mismo y la ciencia como proyecto cultural. 
Así, en conexidad con lo que se plantea la EPE como institución, el proyecto arte de la tierra fortaleció la participación de la comunidad aledaña a la escuela, construyendo redes de trabajo con los abuelos de La Calera y de las plazas de mercado, avivando el reconocimiento de los saberes indígenas y experiencias campesinas del sector. El trabajo autónomo, participativo y propositivo hizo posible una sistematización de experiencias, lo que poco a poco se convirtió en uno de los ejes de nuestra investigación.

Este proyecto se llevó a cabo en el nivel de escuela inicial que acoge niños y niñas entre los 3 y los 6 años. Semanalmente trabajan 16 horas de artes entre actividades de tejido, música, artes escénicas y experiencias artesanales, encaminados al proyecto pedagógico anual denominado Memoria o pensamiento ancestral, parte fundamental dentro de nuestro proceso, ya que las y los estudiantes estaban relacionados con las dimensiones indígenas, afro y campesinas, así como el trabajo de chacanas (símbolo milenario originario de los pueblos indígenas latinoamericanos), el cuidado de la naturaleza y la tierra como fuente de vida y subsistencia. Esto aportó de manera significativa al proceso de aula viva y dio origen a los planteamientos de esta investigación.

\section{Metodología}

Para la construcción de esta investigación se desarrolló una constante reflexión a partir de las necesidades locales del territorio y la medicina ancestral. Bajo una concepción de conocimiento y exploración desde y para la comprensión, se desarrollaron previamente en el aula aprendizajes y construcciones colectivas básicas sobre plantas naturales, saberes ancestrales y procesos de siembra estética, permitiendo al niño o niña acercarse a la realidad desde diferentes aspectos: la creación, la deconstrucción y construcción de la información. La convergencia de estos elementos lleva a pensar en un proyecto donde el conocimiento no se transmite, sino que se construye, relacionando el significado del conocimiento con el significado de la realidad y la vivencia.

Entonces, para hablar de saberes ancestrales y arte, fue necesario recorrer el territorio escolar, el veredal y el de la ciudad. Para ello fomentamos los espacios cada 15 días para recorrer, visitar, preguntar, compartir con otros, reconocernos desde la escucha y el relato de personas de otros lugares que creíamos que no existían. De esta forma, cuando hablamos con los abuelos, en sus casas y en la escuela, logramos reconocerlos como sabedores de la zona. Visitamos algunas plazas de mercado de Bogotá y La Calera donde Martín, de 6 años, dijo: "Me gustó cuando un señor, el de la plaza, nos explicó cómo se hace la panela y la partió y nos la dio a probar, estaba rica y por eso le llevé una a mi mamá". Además de espacios alternativos de propuestas artísticas de educación popular como "casa taller", un lugar de la zona donde se construye con y para la comunidad, sus paredes son hechas de papel reciclado y su huerta está creada para que las personas del barrio se alimenten y sazonen sus comidas.

Todo esto desde la mirada de aprendizaje vivencial, la escuela fuera de la escuela, aprendizajes en contextos no escolares; donde la ciudad es educadora y donde, luego de cada visita, regresábamos a la EPE con nuevas ideas y percepciones, con las preguntas: ¿de dónde vienen los alimentos? ¿ cómo y para qué se siembra?, ¿qué es la medicina de los abuelos?, ¿cómo construimos un espacio de siembra?, ¿qué sucede con nuestro territorio? A partir de estas experiencias empezamos a realizar siembra de plantas propias y orgánicas para el autoconsumo, recuperando el territorio propio escolar como apropiación a los saberes naturales, medicinales y ancestrales que habíamos construido en colectivo; todo esto mediado por la mirada estética y el arte de la tierra. A medida que tejíamos la relación con los anteriores aspectos de la investigación (la creación, la deconstrucción y construcción de la información) cuatro fases de desarrollo orientaron la organización desde el hacer. Primera fase: apertura y exploraciones; segunda fase: reconocimiento y sensibilización del territorio; tercera fase: el alimento y la siembra como proceso de autonomía; cuarta fase: análisis, proceso y conclusiones. Los anteriores aspectos fueron relevantes en la construcción y organización del documento de investigación.

Acerca de arte de la tierra

Intentar una definición del concepto arte procesual puede resultar una tarea algo compleja, si se tienen 
en cuenta las diversas aproximaciones que, alrededor de este, se han realizado desde distintas disciplinas y diferentes corrientes de pensamiento, las cuales algunas veces se relacionan entre sí y otras se oponen o se distancian considerablemente.

Desde el ámbito artístico, se plantea que el concepto arte procesual desde la concreción de unas acciones expresivas en las cuales lo más importante es el desarrollo, el proceso de la creación, y no tanto la culminación de una obra o de un producto estético característico de las artes plásticas objetuales (dibujo, pintura, escultura tradicional). En opinión de Guash (2000), esta acepción implica la valoración de la dimensión temporal en lo relacionado con la ejecución de un proyecto artístico y, además, la comprensión de la importancia que en esta orientación adquiere el espacio o ambiente en el cual se ejecutan las acciones que constituyen la esencia de dichos proyectos. Ahora bien, este hecho confiere a dichos procesos el carácter de obra única, irrepetible y por lo general efímera. Lo cual, en sus orígenes, situados a finales de la década de 1960, constituyó, en opinión de la autora, toda una erosión en los valores estéticos instituidos en el arte occidental a lo largo de la modernidad.

Con respecto al concepto de arte de la tierra, si bien presentaban un enfoque genérico y básico en este tipo de estudios, actualmente nuestros intereses en estos ámbitos se han orientado en otras direcciones. En efecto, para abordar nociones más recientes acerca del arte de la tierra hemos considerado pertinente hacerlo a la luz de los planteamientos desarrollados por autores como July Barrero y Astrid Medina (2014) quienes han propiciado un gran debate sobre la pertinencia de dicho concepto en la actualidad.

Se debe recalcar que a partir de la tendencia arte de la tierra se han realizado diversas exploraciones personales, en esta ocasión retomamos la del docente Gary Gari Muriel (2010), (docente UDFJC) como la planteada en el colegio Julio Garavito Armero, logrando generar experiencias artísticas a través de expresiones plásticas y visuales efímeras de tendencias contemporáneas, considerando la relación que se establece entre el ser humano y su entorno natural apostándole a la transformación de contextos, siendo este proyecto acogido por la
Secretaría de Educación de Bogotá como experiencia significativa dentro del Festival Artístico Escolar. Así, se han generado nuevos procesos y proyectos de investigación a partir de dicha tendencia. A continuación, hacemos un recuento general del trabajo de Muriel para retomar sus análisis y sus experiencias, haciéndolas parte del marco de antecedentes de nuestro proyecto en pro del reconocimiento, la conservación, la creación y la reflexión a partir de la relación arte-naturaleza-siembra.

Como punto de partida tenemos el trabajo generado en el Gimnasio Real de Colombia, Aguilera (2015), con estudiantes del nivel de transición denominado Arte de la tierra para potenciar la conciencia ambiental de la primera infancia en el Gimnasio Real de Colombia, a partir del cual se plantea la reflexión sobre la huella que estamos dejando en el entorno. Lo anterior en busca de una reconfiguración entre la sociedad y el ecosistema teniendo en cuenta diversos dispositivos pedagógicos del entorno natural que, como lo menciona la autora, produce angustia y parálisis.

\section{Acerca de SembrArte}

Este concepto, creado por nosotros como colectivo, hace énfasis al proceso de siembra y el arte, desde el conocimiento del uso común y el cuidado del entorno a través del arte como lenguaje expresivo, recuperando el espacio físico y la re-significación de lo natural como parte de la identidad y la valoración desde lo estético como palabra intencionada. En este caso fue indispensable analizar no solo el proceso natural que conlleva el sembrar sino la distribución, el contraste de colores, tamaños y formas. Es relevante que los niños y niñas entiendan a partir de la filosofía indígena que somos seres de la tierra y que debemos vivir en armonía, entiendo a la tierra como elemento fundamental de la vida.

Fue importante comenzar a abordar este término desde lo ancestral, recuperando la memoria sobre el territorio, los grupos indígenas, afro-descendientes y campesinos. Al observar la diversidad de climas y suelos evidenciamos gran variedad de alimentos y formas de siembra y creación, pues la riqueza de la tradición oral y el hacer con tradición y significado es relevante para forjar identidad y apropiarla desde la etapa inicial, para lograr tener 
así unas raíces fuertes, una conciencia y reflexión sobre lo que hacemos y ¿cómo lo hacemos? Abordando prácticas propias sobre el territorio, en el cual se inician observaciones del espacio en que estamos inmersos; teniendo en cuenta aspectos como la luz, la temperatura, la humedad, disposición de la tierra y demás elementos; teniendo como eje fundamental la creación y el arte de la siembra; tomando percepciones de siembra propias con el arte como fundamento en el proceso.

La palabra sembrarte nace de la necesidad de sembrarse artísticamente, de colocarnos como semillas en la tierra, para entender de la forma más sencilla y agradable del proceso donde la raíz necesita y vive dentro de la tierra. Así, nuestros acercamientos con el ambiente se entienden desde el proceso natural de la semilla, las cuales forman parte del origen y del fruto.

Con estos conceptos y reflexiones se inicia la creación de los semilleros, los cuales nacen a partir de observar el cuidado de lo pequeño, acercándonos a la paciencia y la participación del territorio en proceso.

\section{Aula viva}

Esta es entendida como una experiencia pedagógica, la cual construye y relaciona conocimientos a través del hacer dinámico y socializador. Si bien el concepto de aula nos trae a la imaginación la relación de conocimiento, cuatro paredes, asientos y una pizarra, vemos que existen espacios de aprendizaje fuera de la escuela donde las paredes de la ciudad y el campo se convierten en las propias pizarras, donde los asientos son las calles y los aprendizajes se generan con los habitantes de los territorios. Es de esta forma que vivenciamos con los niños y niñas de la EPE la relación entre hacer y aprender, generando así nuevos procesos conscientes en relación directa con su entorno y realidad. Y a partir de estas vivencias es que el niño y la niña logran preguntarse, crear hipótesis, explorar y descubrir con otros. Por ello, para nuestra investigación este punto es de gran relevancia, ya que el infante aprende en interacción, manipulando, observando y hablando con la comunidad.

En este sentido se ha relacionado el significado del conocimiento con el significado de la realidad, comprendiendo, resignificando información y construyendo conocimiento desde la experiencia, reorientando las prácticas de clase para trabajar desde los intereses y las necesidades del colectivo.

\section{La huerta}

La creación de huerta surge a partir de la invención conjunta sobre la narrativa ancestral. El diseño del espacio se hizo a partir de una historia inventada por los niños y niñas que expone lo siguiente: un círculo en madera que representa al sol y, desde la tradición, al hombre indígena; la luna construida con piedras, como representación del cielo y como transformación desde la esencia de la mujer; y, por último, la canoa elaborada en madera como objeto de navegación y descubrimiento. Esto de la mano de la creación esencial del color natural y los contrastes de las plantas, donde los niños y niñas, a partir de las recomendaciones de los abuelos, empezaron a sembrar caléndula, lechuga verde y morada, chía, alverjas, zanahoria, apio, cilantro, menta, toronjil, entre otras. Pero no se sembró de cualquier forma, se tuvieron en cuenta los saberes ancestrales desde: los rituales, el calendario lunar, las plantas que aíslan a las plagas, los sistemas de riego y afecto con el entorno. $Y$ desde el componente artístico se combinaron los colores de las plantas, para dar una ilusión de mosaico, se pintaron murales y se dibujó en las bateas ${ }^{7}$; todo esto entendiendo que cada planta posee un crecimiento y cuidado distinto, frente a diversos haceres artísticos y ancestrales.

En este sentido, la experiencia y el juego con la naturaleza nos dio la posibilidad de trabajar de manera artística los procesos propios de la siembra, espirales, zigzag y ondas; así como la recreación de chacanas naturales que ampliaron las posibilidades creativas tales como: la adecuación de cercas naturales con la curuba, aprovechando el crecimiento de plantas como enredaderas se

\footnotetext{
Término utilizado por los abuelos de la zona para referirse a un recipiente de madera utilizado para sembrar. Estas bateas se diseñaron desde la creación de los niños y niñas, teniendo en cuenta la altura precisa para el fácil acceso para que ellos visiten, rieguen y cuiden su propia siembra.
} 
enriqueció el hacer estético del ambiente de la huerta al tiempo que sembrábamos alimentos limpios y orgánicos para el autoconsumo ${ }^{8}$, aportando al cambio y enriquecimiento del territorio como reconocimiento de lo propio y lo colectivo con un impacto visual.

\section{¿Que se evidenció? ¿ ¿qué se transformó?} $\mathrm{Al}$ inicio del proceso evidenciamos:

1. Que los niños y niñas tenían una relación con su entorno natural desde lo turístico, pues tenían claridades de los nombres de los espacios y qué actividad realizaban en el arenero de colores, en las piedras, en los árboles caídos, pero no entendían el espacio como territorio que cuenta, como cuidado y recurso. El ambiente natural en la EPE es entendido como sistema de interacciones, por cuanto es allí donde se abordan las problemáticas ambientales que se evidencian al interior de la comunidad. Y aquí observamos una discontinuidad en lo que se plantea como institución y lo que los niños y niñas elaboran desde sus percepciones y prácticas diarias escolares.

Así, se logra evidenciar en cada una de las intervenciones que a lo largo de nuestro proceso cada niño y niña de manera individual y en conjunto transformó su noción de naturaleza y entorno: pasando de concepciones de lo artificial a lo natural y esencial; reconociendo a las plantas como medicinales capaces de realizar transformaciones y curaciones; entendiendo al territorio como relato que cuenta, por ejemplo, la invasión de los pinos que resecan la quebrada de la EPE; considerando al territorio como parte de todos; y contemplando la naturaleza como un proceso cercano de cambio físico, estético y natural.

\footnotetext{
Autoconsumo fue un término que utilizamos con los niños y niñas de la EPE para referirnos a la importancia de sembrar y cultivar nuestros propios alimentos. Esto desde el trabajo en la tierra, reflexionando acerca la producción propia como parte del proceso de alimentación seguro, estable y nutritivo que satisfaga toda su necesidad, lo cual es difícil cuando no todas las personas poseen un acceso a la tierra, al trabajo de esta y a las semillas orgánicas.
}

2. Se evidenció que la comunidad escolar no teje de forma continua lazos entre el saber tradicional y el saber académico, pues la mayoría de discursos estaban mediados por el maestro de Biología o Química, y estos eran los encargados de dirigir actividades de granja y siembra desde una mirada antropocéntrica que en ocasiones derivaba en prácticas egoístas y simplistas de individualismo frente al entorno natural. A partir de lo anterior, apostamos por una articulación armónica desde la mirada académica, el hacer ancestral y las posibilidades individuales con las responsabilidades colectivas, pues traer a los sabedores a la escuela fue relevante para reconocer el discurso cotidiano que se mueve en la ciudad y el campo. Lo anterior es abrir el espacio para la escucha y el reconocimiento, donde todos tenemos algo que decir y aprender, donde la escuela es en sociedad, donde la experiencia de visitar las plazas de mercado posibilitó un ambiente armónico que permitió que la información se convierta en una herramienta significativa para todos. Esto no solamente para entender una problemática o un fenómeno, sino que dé paso a una transformación del aprendizaje articulándose a las actividades socioculturales en las que nos desenvolvemos como seres sociales capaces de mantener condiciones de vida adecuadas para nosotros mismos y los demás seres vivientes. Entender que somos una escuela al servicio de la sociedad y una sociedad que construye la escuela.

3. En la creación ambiental es necesario, dentro del desarrollo del hacer artístico, relacionar problemáticas con experiencias. Al hablar de la importancia de la alimentación se observa que actualmente la preocupación por la educación ambiental se acrecienta por momentos y son varias las razones para ello. Por una parte, nos encontramos frente a la necesidad de garantizar la vida de los seres humanos en condiciones adecuadas y dignas; por otra, el agotamiento de los recursos naturales, el cuál es un hecho que hace que pensemos con urgencia en nuestras relaciones con el entorno, nos situó en la recuperación del territorio y la apropiación de nuestros alimentos. Así, como 
resultado material se deja en la EPE una huerta estética que observa un sistema de siembra de plantas medicinales: teniendo en cuenta la práctica agrícola y la recuperación del territorio que es de todos; entendiendo que la tierra es de quien la trabaja y los alimentos son de quien los siembra y cosecha; que estas siembras son comunitarias; aprendiendo del agua Iluvia como hidratación y alimento de nuestra huerta; aprendiendo de los residuos sólidos y de estas interrelaciones es que se generan entre ambiente y sujeto; desde este trabajo experiencial fue necesario tomar y aplicar elementos como los de aire, luz solar, agua y compostaje, entendiendo estos como recursos naturales para el fortalecimiento de la huerta y la siembra; aprendiendo de los tiempos que cada una de las plantas desde su proceso de siembra como semilla hasta su cosecha y fruto, el cuidado y mantenimiento que cada una de ellas teniendo así la distribución en la siembra para el crecimiento oportuno; observando la importancia y los beneficios que cada una de las plantas cosechadas brinda al ser humano, ya sean de aporte nutritivo o medicinal; articulando conocimientos académicos y saberes tradicionales con el fin de promover la sostenibilidad ambiental y generar productos alimenticios limpios y plantas con creencias medicinales para el autoconsumo, fortaleciendo el tejido social.

Como propósito inicial de afianzar la conciencia ambiental, vivenciar y entender el proceso de siembra orgánica a partir de los procesos de creación con elementos naturales en estudiantes de escuela inicial, se evidenció una transformación significativa en cuanto a sus discursos y haceres. Los niños y niñas se comenzaron a proyectar como parte del territorio, cuidando el entorno natural próximo y realizando acciones cotidianas tales como lo manifiestan: "profe, es importante sembrar para tener nuestros alimentos", "me gustó cuando sembramos con lechugas de colores y quedó un espiral", "amigos, vamos a regar las plantas, hoy nos corresponde a nosotros", "profe, mira que yo sembré una planta mágica en mi casa para cuando nos de dolor de panza", "nosotros cuidaremos mucho nuestra huerta y le enseñaremos a nuestros padres", "cuando recogimos, bueno cosechamos con mi papá, mi mamá y mi prima, cuando ellos vinieron a la escuela llevamos a la casa unas lechugas y mi mamá las hizo con tomate, a mí sí me gustaron".

\section{Conclusiones}

Con respecto a la siembra estética asumida conscientemente de forma medicinal, logramos construir un nuevo saber desde la cura de enfermedades, cómo estas representan algo en nuestro cuerpo y cómo no siempre existieron las pastillas y jarabes industriales; pues las plantas también nos pueden curar dolor de panza (hierba buena) o cabeza (laurel). También se entendió el proceso alimenticio desde la importancia de sembrar y consumir de manera colectiva y autónoma. Esto nos dio la posibilidad de transformar espacios, así como la construcción a partir de saberes divergentes, recuperando las percepciones y la voz del niño como sujeto de saber, involucrando y enriqueciendo el tejido social como parte de la identidad y la historia desde los ámbitos educativos, artísticos, ambientales y culturales.

Además de transformar la clase tradicional, transfigurando la vivencia como aula viva a través de creaciones posibles en que el entorno natural se convirtió en un cúmulo de experiencias enriquecedoras, al igual que los aprendizajes fuera de la escuela, los cuales nos permitieron reivindicar y repensar nuestro hacer social con conciencia y sentido; ampliando la concepción de lo natural y lo estético como parte de un todo constante y cambiante.

Por otra parte, este proceso queda en punta como aula activa y continúa en la institución EPE, el cual permitió que los maestros de Educación Artística y Ciencias Naturales comenzaran a pensarse en un espacio de arte abierto e innovador, ampliando tanto el reconocimiento como la valoración de lo propio.

Otra conclusión, desde la formación universitaria, se genera al presentar el proyecto de LPI de la UDFJC y cómo se dio esta experiencia, con el fin de lograr una reflexión y conversación interna en 
los docentes en formación acerca de las metodologías y consideraciones del arte, como estrategias y alternativas divergentes que enriquecen tanto el proceso de estudiantes como la importancia de la investigación en el rol docente a partir del hacer vivencial y creativo por medio de la naturaleza, el tejido del relato y la apropiación del territorio.

\section{Referencias}

Aguilera, D. M. (2015). Arte de la tierra para potenciar la conciencia ambiental de la primera infancia en el Gimnasio Real de Colombia (Trabajo de grado). Licenciatura en Pedagogía
Infantil, Universidad Distrital Francisco José de Caldas, Bogotá.

Barrero, J.; Medina A. (2014). Arte de la tierra para afianzar la conciencia ambiental en estudiantes de 5 de básica primaria (Trabajo de grado). Licenciatura en Pedagogía Infantil, Universidad Distrital Francisco José de Caldas, Bogotá.

Gari Muriel, G. (2010). Arte de la tierra en el Julio Garavito Armero. En, Experiencias artísticas que transforman contextos en los colegios de Bogotá. Bogotá: Festival Artístico Escolar, SED.

Guash, A (2000). El arte del último siglo XX. Madrid: Alianza Forma. 


\section{Anexo}

A continuación, se evidencia cómo se dio el proceso de huerta estética a partir de varios elementos:

Tabla 1. Listado de plantas medicinales, beneficios, cantidad de siembra a partir de la creación, la percepción estética y cuidados por los campesinos de la zona. (EPE Km 4,5 vía La Calera).

\begin{tabular}{|c|c|c|c|}
\hline $\begin{array}{l}\text { Nombre de } \\
\text { la planta }\end{array}$ & Beneficios & Cuidado & Sentido estético \\
\hline Caléndula & $\begin{array}{l}\text { Esta planta es medicinal, ya que era usada por } \\
\text { los griegos y romanos para curar enfermedades. } \\
\text { La caléndula sirve para curar heridas, estimula la } \\
\text { acción cicatrizante y regenera la piel dañada, así } \\
\text { como también permite producir más colágeno, } \\
\text { Se usa, entonces, para las cicatrices, suavizantes } \\
\text { y calmantes, reduce las inflamaciones }\end{array}$ & $\begin{array}{l}\text { Es una planta rústica, } \\
\text { la cual necesita para su } \\
\text { correcto desarrollo un } \\
\text { lugar húmedo. No soporta } \\
\text { heladas por debajo de } \\
\text { los } 4^{\circ} \text {. Necesita de suelos } \\
\text { que drenen muy bien, } \\
\text { donde nunca se produzcan } \\
\text { encharcamientos. } \\
\text { No necesita de grandes } \\
\text { cantidades de abono } \\
\text { orgánico. }\end{array}$ & $\begin{array}{l}\text { Se sembraron } 15 \text { plantas } \\
\text { de caléndula, teniendo en } \\
\text { cuenta su color anaranjado } \\
\text { con centro amarillo y } \\
\text { su gran altura, para dar } \\
\text { profundidad y armonía en } \\
\text { el espacio visual formando } \\
\text { así un rededor de un color } \\
\text { continuo. Además de lo } \\
\text { anterior, se dio también con } \\
\text { un fin ambiental el cual } \\
\text { consistió en el control de } \\
\text { plagas, ya que la caléndula } \\
\text { es amarga y llegan primero } \\
\text { a ella que está externa que } \\
\text { al interior de la matera. } \\
\text { Se ubicaron } \\
\text { estratégicamente alrededor } \\
\text { de la canoa la cual está } \\
\text { levemente levantada del } \\
\text { suelo. }\end{array}$ \\
\hline $\begin{array}{l}\text { Lechuga } \\
\text { verde }\end{array}$ & $\begin{array}{l}\text { Es esencial que sepamos la importancia que tiene } \\
\text { la lechuga en función de nuestro organismo, ya } \\
\text { que se puede considerar un súper alimento con } \\
\text { un sinfín de propiedades y beneficios. } \\
\text { Contiene una gran cantidad de hierro, Se } \\
\text { recomienda consumirla también cuando se sufre } \\
\text { de estados gripales o resfríos, ya que fortalece las } \\
\text { vías respiratorias combatiendo y previniendo la } \\
\text { fatiga, el cansancio y la anemia. }\end{array}$ & $\begin{array}{l}\text { La lechuga exige un suelo } \\
\text { rico en nutrientes, que } \\
\text { drene bien, crece en los } \\
\text { climas húmedos y frescos. } \\
\text { Necesita tierra ligera, } \\
\text { con buen drenaje, } \\
\text { plantar semillas ácidas } \\
\text { para evitar el ataque de } \\
\text { microorganismos. }\end{array}$ & $\begin{array}{l}\text { Se sembraron } 20 \text { lechugas } \\
\text { de color verde ubicadas } \\
\text { en zigzag en la matera de } \\
\text { ladrillo la cual tiene forma } \\
\text { de luna y la cubre musgo } \\
\text { en la parte de afuera; por } \\
\text { tal razón estos colores vivos } \\
\text { resaltan y dan movimiento } \\
\text { logrando que estos } \\
\text { elementos se destaquen } \\
\text { sobre el color de la tierra. }\end{array}$ \\
\hline $\begin{array}{l}\text { Lechuga } \\
\text { morada }\end{array}$ & $\begin{array}{l}\text { La lechuga morada tiene propiedades } \\
\text { medicinales fascinantes, una forma de disfrutar } \\
\text { de la gastronomía y, a su vez, cuidar de nuestra } \\
\text { propia salud. } \\
\text { Es excelente para luchar contra la retención de } \\
\text { líquidos lo que también es favorable no solo en } \\
\text { el día a día, sino también para esas personas que } \\
\text { quieren reducir peso y volumen. } \\
\text { Esta lechuga es rica en antioxidantes por lo } \\
\text { que podemos afirmar que mejora la salud y } \\
\text { flexibilidad de las paredes de las venas y las } \\
\text { arterias. } \\
\text { Además, favorece la prevención de las } \\
\text { enfermedades cardiovasculares y degenerativas, } \\
\text { reduce el riesgo de desarrollar tumores y tiene } \\
\text { efectos antiinflamatorios. }\end{array}$ & $\begin{array}{l}\text { Se desarrolla bien en } \\
\text { climas templados frescos, } \\
\text { es muy sensible a la falta } \\
\text { de humedad, no soporta } \\
\text { periodos de sequía, prefiere } \\
\text { suelos ligeros, arenosos y } \\
\text { con buen drenaje, suelo } \\
\text { fértil. } \\
\text { Se recomienda tener } \\
\text { precaución con las plagas y } \\
\text { las enfermedades, para ello } \\
\text { se establecieron estrategias } \\
\text { de recolección de caracoles } \\
\text { y trasladarlos de hábitat } \\
\text { formando caracolarios o } \\
\text { llevándolos al bosque. }\end{array}$ & $\begin{array}{l}\text { Se sembraron } 8 \text { lechugas } \\
\text { moradas las cuales se } \\
\text { encuentran intercaladas con } \\
\text { las verdes logrando así un } \\
\text { zigzag colorido y armonioso } \\
\text { visualmente, construyendo } \\
\text { un camino el cual se } \\
\text { observa a gran distancia. }\end{array}$ \\
\hline
\end{tabular}




\begin{tabular}{|c|c|c|c|}
\hline Hierbabuena & $\begin{array}{l}\text { La hierbabuena es más } \\
\text { famosa por su uso en el alivio } \\
\text { de problemas estomacales. } \\
\text { Es un antiespasmódico, la } \\
\text { hierbabuena puede ayudar a los } \\
\text { trastornos del sistema digestivo } \\
\text { incluyendo gases, distensión } \\
\text { abdominal, náuseas, indigestión } \\
\text { y cólicos. Los estudios han } \\
\text { demostrado que la hierbabuena } \\
\text { es incluso efectiva para aliviar el } \\
\text { síndrome del intestino irritable. }\end{array}$ & $\begin{array}{l}\text { Es fundamental elegir } \\
\text { correctamente el lugar donde } \\
\text { se ubicará la planta para que } \\
\text { crezca fuerte y sana. } \\
\text { Esta planta aromática } \\
\text { necesita recibir abundante } \\
\text { luz solar, requiere un riego } \\
\text { abundante. } \\
\text { Es por ello que se debe regar } \\
\text { a diario. }\end{array}$ & $\begin{array}{l}\text { Se sembraron } 6 \text { plantas de } \\
\text { hierbabuena, las cuales se } \\
\text { distribuyeron alrededor de la } \\
\text { matera de luna teniendo en cuenta } \\
\text { que esta tiene gran tamaño. El } \\
\text { color oscuro de la planta nos } \\
\text { permitió distribuirla por los bordes } \\
\text { generando así una cerca al zigzag } \\
\text { quedando esta forma como una } \\
\text { chacana a gran escala. }\end{array}$ \\
\hline Perejil & $\begin{array}{l}\text { Entre sus usos medicinales } \\
\text { podemos encontrar como } \\
\text { tratamiento natural para limpiar } \\
\text { los riñones, ya que esta planta } \\
\text { tiene grandes propiedades } \\
\text { diuréticas. } \\
\text { El perejil contiene minerales } \\
\text { como el calcio, hierro, fósforo } \\
\text { y azufre. Por su alto contenido } \\
\text { de hierro se recomienda su } \\
\text { consumo a las personas que } \\
\text { padecen o son propensas a } \\
\text { padecer de anemia y/o anorexia, } \\
\text { y también a aquellas que sufren } \\
\text { de debilidad, fatiga o cansancio } \\
\text { físico. }\end{array}$ & $\begin{array}{l}\text { El perejil debe tener } \\
\text { suficiente humedad, sus } \\
\text { raíces se adhieren bien en } \\
\text { tierra fría, no le debe dar el } \\
\text { sol directamente; el suelo } \\
\text { debe ser preferiblemente } \\
\text { arcilloso evitando los } \\
\text { encharcamientos de agua. }\end{array}$ & $\begin{array}{l}\text { Se sembraron } 6 \text { plantas de perejil } \\
\text { en la maceta circular (el sol), se } \\
\text { pensó en sembrar el perejil por } \\
\text { su color y tamaño, el cual se } \\
\text { distribuyó en forma de espiral } \\
\text { marcando su camino con piedras } \\
\text { blancas y amarillas como rayos } \\
\text { de luz, siendo estas de tamaño } \\
\text { mediano con formas naturales } \\
\text { traídas del bosque. }\end{array}$ \\
\hline $\begin{array}{l}\text { Hierba aromática } \\
\text { (Aromática, romero } \\
\text { y tomillo) }\end{array}$ & $\begin{array}{l}\text { Calientes o frías, las ancestrales } \\
\text { aguas aromáticas son más que } \\
\text { bebidas que aportan calor o } \\
\text { refrescan. Entre sus múltiples } \\
\text { propiedades se destaca que } \\
\text { son relajantes, antioxidantes, } \\
\text { hidratantes y reconstituyentes. } \\
\text { Muestra de ello son las } \\
\text { tradicionales recomendaciones } \\
\text { de las abuelas: el agua de } \\
\text { hierbabuena, para los dolores } \\
\text { de estómago y la pesadez } \\
\text { estomacal; la de caléndula, para } \\
\text { la gastritis, y la de canela, para } \\
\text { los cólicos menstruales. }\end{array}$ & $\begin{array}{l}\text { Necesitan una tierra húmeda } \\
\text { y fría, su riego debe ser en } \\
\text { las horas de la mañana o el } \\
\text { atardecer, evitando cuando } \\
\text { hay bastante sol; los riegos } \\
\text { para eliminar sus plagas } \\
\text { deben hacerse en horas } \\
\text { de la noche y retirarlos } \\
\text { con abundante agua luego } \\
\text { de dos o tres días si van } \\
\text { hacer utilizadas para el } \\
\text { autoconsumo. }\end{array}$ & $\begin{array}{l}\text { Se sembraron } 12 \text { plantas distintas, } \\
\text { con variadas formas y colores } \\
\text { con las que creamos una forma } \\
\text { irregular con colores intercalados, } \\
\text { realizando unas subidas y bajadas } \\
\text { que se observaban como una onda } \\
\text { con colores consecutivos claros y } \\
\text { oscuros. }\end{array}$ \\
\hline $\begin{array}{l}\text { Arvejas } \\
\text { (Llamadas por } \\
\text { los niños y niñas } \\
\text { Alverjandras). }\end{array}$ & $\begin{array}{l}\text { Las arvejas se pueden consumir } \\
\text { frescas o secas presentando } \\
\text { algunas diferencias significativas } \\
\text { respecto a su contenido en } \\
\text { nutrientes. Ya que aporta } \\
\text { cantidades considerables de } \\
\text { hidratos de carbono. }\end{array}$ & $\begin{array}{l}\text { El clima ideal es templado a } \\
\text { templado frío, es relevante } \\
\text { pensar en los suelos fértiles } \\
\text { y húmedos. Las semillas se } \\
\text { siembran con una distancia } \\
\text { de más o menos } 30 \mathrm{~cm} \text {. }\end{array}$ & $\begin{array}{l}\text { Se sembraron } 18 \text { arvejas en la } \\
\text { cerca de la huerta, ya que estas } \\
\text { poseen propiedades trepadoras y } \\
\text { logramos hacer que estas crecieran } \\
\text { y se enredaron en los alambres, de } \\
\text { forma abundante tejiendo una raíz } \\
\text { fuerte en la tierra, construyendo } \\
\text { así una cerca natural la cual se } \\
\text { transforma a partir de su proceso } \\
\text { de cosecha, logrando variar sus } \\
\text { colores durante el año desde } \\
\text { el verde claro hasta el amarillo } \\
\text { oscuro. }\end{array}$ \\
\hline
\end{tabular}

